\title{
CROSSING AND DIPPING: Some Terms for Approaching the Interface between Natural Understanding and Logical Formulation
}

\author{
E.T. Gendlin \\ University of Chicago \\ (Mind and Machines Vol.5, 547-560, 1995.)
}

\begin{abstract}
Gendlin proposes experimental concepts as bridges between phenomenology and logical formulation. His method moves back and forth, aiming to increase both natural understanding and logical formulation. On the subjective side, the concepts require direct reference to felt or implicit meaning. There is no equivalence between this and the logical side. Rather, in logical "explanation", the implicit is carried forward, a relation shown by many functions. The subjective is no inner parallel. It performs specific functions in language. Once these are located, they also lead to developments on the formulated side.

To show some of this, Gendlin modifies Lakoff and Johnson's theory of metaphor, and expands it into a theory of all language use. He denies that a metaphor consists of a pattern or image, shared by two situations. There is only one situation - the metaphoric one. The original situation is actually a family of many uses (in the Wittgensteinian sense). As in all speech, a word makes sense only as its use-family "crosses" with an actual situation in the actual spot in a sentence. Subjectively, a metaphor means this crossing. From it, long chains of new similarities and differences can be generated. Ways to study the functions and features of this crossing are proposed.
\end{abstract}

\section{Introduction}

Let me begin with a familiar story: Suppose you have an oddly gnawing feeling. Then you realize - oh, it's that you forgot something -- it's now Monday afternoon -- what was it? You don't know, and yet it is there, in that gnawing body-tension. You think of many things you ought to have done today, but no; none of them are "it." How do you know that none of these is what you forgot? The gnawing knows. It won't release. You burrow into this gnawing. Then suddenly -- you remember: Yes, someone was waiting for you for lunch. Too late now! This might make you quite tense. But what about the gnawing? That particular tension has eased. The easing is the easing of that gnawing. Its easing is how you know that you have remembered. Remembering is something experienced, and the term "remembered" is used in direct reference to experience.

Of course, there are outward indications of remembering, for example your apologetic phone call. In experiments remembering is defined by some outwardly performed reproduction. Terms that refer directly to experience have many relations to terms that are defined in other ways. But these two kinds of terms are not parallel. If they were, we would not need both kinds. 
Another example: Consider a poet, stuck in midst of an unfinished poem. How to go on? The already written lines want something more, but what?

The poet reads the written lines over and over, listens, and senses what these lines need (want, demand, imply .....). Now the poet's hand rotates in the air. The gesture says that. Many good lines offer themselves; they try to say, but do not say --that. The blank is more precise. Although some are good lines, the poet rejects them.

That ..... seems to lack words, but no. It knows the language, since it understands -and rejects --these lines that came. So it is not pre-verbal; Rather, it knows what must be said, and knows that these lines don't precisely say that. It knows like a gnawing knows what was forgotten, but it is new in the poet, and perhaps new in the history of the world.

Now, although I don't know most of you, I do know one of your secrets. I know you have written poetry. So I can ask you: Isn't that how it is? This ..... must be directly referred to (felt, experienced, sensed, had, .....). Therefore, whatever term we use for such a blank, that term also needs our direct reference.

The blank brings something new. That function is not performed by the linguistic forms alone. Rather, it functions between two sets of linguistic forms. The blank is not just the already written lines, but rather the felt sense from re-reading them, and that performs a function needed to lead to the next lines. A second function: If that stuck blank is still there after a line comes, the line is rejected. Thirdly, the blank tells when at last a line does explicate -- it releases.

Between the subjective and objective sides there is not a relation of representation or likeness. The words don't copy the blank. How can a set of words be at all like a blank? Rather, what was implicit is changed by explicating it. But it is not just any change. The explication releases that tension, which was the ...... But what the blank was is not just lost or altered; rather, that tension is carried forward by the words. Of course the new phrases were not already in the blank. They did not yet exist at all. When they come they are much more than the blank was, but not just different, either. Just now, my phrase "carrying forward" worked as a term to say this relationship.

I must emphasize that this relation of carrying forward is not an equality. The felt sense is not just a subjective equivalent of the language. The two sides perform very different functions.

Let me say why this inequality, this carrying forward relation is so important: If the subjective and the formulated sides were equal, then the subjective side would be superfluous. Perhaps we would be interested in the subjective side for sentimental reasons -- since we are it, but it would have no function that the objective side doesn't already perform.

Instead, we saw this subjective side -- the direct referring -- performing a number of functions so far:

We saw it letting us know that something was forgotten. We saw it rejecting proposals for what that was, and then also letting us know that we had indeed remembered. We saw it enabling already written lines to say more than was as yet 
written. We saw that it rejected perfectly good lines, and eventually also that it was carried forward by certain lines. We saw that such carrying forward can say something new. In the rest of my paper I will show more such specific functions.

I have also used some terms to speak of this subjective side. I said that a felt sense is a direct referent, that its implicit meaning is not copied by, or equal to its explication, but rather carried forward by explication. (For more on these terms, see Gendlin 1970, 1991).

These bridge-terms are patterns, of course, but they also have a subjective side. They depend on your direct reference to their subjective side, in order to let you think about the special functions that side performs in cognition. We need such terms in all the social sciences and in cognitive science. Let me show the need for them in regard to the field of artificial intelligence.

I am not concerned with the ideological issue, whether we should foretell a future in which computers can replace human intelligence, and whether that would be good, or whether it will become clear that this is impossible, and also, that it would be bad. Rather, I am concerned with the interface between our natural understanding and the realm of logical forms. To become able to handle this interface, we must become able to think on both sides.

Of course, the kind of concepts will be different on the two sides. On the logical side they are seemingly clean patterns, an overlapping fan of types: binary choices, algorithms, diagrams in space, whatever can seem to be "the same" when it recurs. The other side includes all these, at least implicitly, but not as they seem to work alone, rather along with what is involved in using them -- freshly each time, so that they always say and do more than can be logically rendered.

Already my metaphor of two sides has changed: Since the natural side includes how the logical forms function in and with it, the distinction is not like a division between two things in space. The concepts of the natural side are bridge-concepts of both. They are concepts on the interface. Notice that my two sides are not in any way duplicates of each other. We would not need the natural side, if it were a mere subjective duplicate of what can be logically formed and built externally.

Wittgenstein's thought-experiments showed that we need no inner duplicate. In a more recent such thought-experiment you are asked to imagine a hidden computer whose responses in all circumstances satisfy every inquirer that it knows english. Then its lack of subjective knowing becomes a metaphysical mystery, or seems simply unnecessary. But that applies only if we were satisfied with what has already been put into logical form. If instead, as is the case, we must constantly dip into subjective or natural knowing in order to formulate more and more of it, then it is not a good idea to pretend that all understanding is already in logical terms. Then our dipping becomes secret.

Why not study that process of dipping by which we formulate more and more of it? It does not need to be left blank. 
At present, dipping is largely left as if it were a private matter. When we ask someone how they did it, they might say: "It came to me in the shower." But let us have at least one term to name this dipping. If we could develop more terms, good terms for what is involved in dipping; we could do it better.

For example, recently some people greatly improved chess-playing computers. How did they do it? Let us say they asked chess masters why they chose a given strategy at that point. The masters dipped into their felt sense of so choosing, and found many reasons implicitly functioning together as one felt sense of knowing what move to make. They could explicate some of these many pre-separated factors, and one of them was that they chose certain strategies because it was early in the game, other strategies late in a game. That could then be built into the program. Now that it is formulated, we can reverse the order in which it was found: We can claim that the chess-master does exactly what the computer does. In regard to this specific dimension, the subjective side can be said to be superfluous, merely metaphysical. But we want more of those dimensions. The argument, whether there is ultimately such a thing as "all" dimensions, can be shelved.

This discussion applies to social science methodology generally, not just to artificial intelligence. Social science seeks to formulate human behavior. The variety of kinds of concepts is greater than in artificial intelligence, but social science requires some kind of logical forms. The corresponding argument I wish to shelve, is whether a science of humans is possible. Those who say yes think they have to deny anything that cannot be formulated today, including much of the human subject. Conversely, those who defend the human subject think they have to say no, ultimately there cannot be a science of humans. Meanwhile our science is already quite powerful but greatly in need of better formulations.

Could we not agree that the universe somehow does include human subjects -since we're here -- and think not only in logical terms that seem to work alone, but also to develop terms for thinking that which can not (or not yet) be rendered in separable logical forms?

But the ideological divide runs deep: Each side is almost offended by the mere mention of the other. One side is thoroughly upset by any talk about something that cannot be rendered logically. But the other side will fight if I add one little word in front, and talk about what cannot yet be rendered logically. However, both sides will be better served by becoming able to think on the interface.

The issue whether computers can ever replace persons, is metaphysical. Instead, we could study the system that consists of computer + person. That is the only real situation, after all. Here I cite Sterner's (1990) principle: "While the ideas for a program can be expressed in an abstract "pseudo" language that is not yet intelligible to a computer, and while it is certainly possible to construct groups of program statements that make a computer do things of no particular consequence, the synthesis of these two yields a functional unity we call a computer application that performs useful actions."

That the system computer + human has hardly been studied can be seen everywhere. The technology in the designs of computers alone is brilliant; the computer/human interface is handled almost without thought. On a simple word- 
processing keyboard some most frequently used keys are small and placed between others that are more rarely used. Obviously there was no research on the system that comprises computer + typist. So much more is this missing when, for example, one wants to build a computer that will understand the natural language. Currently this is thought about in terms of computers replacing the people. In these terms the computer/person system does not appear and cannot be studied.

Since only the rump-system -- the computer alone -- is studied, there has been no research on the functions of the person in any actual computer-system. We have not studied the person in the context of the computer-person system. Therefore we do not have very extensive or very relevant terms for the many functions of natural language and thought.

The gap between natural language and computers exists also in cognitive psychology and cognitive science generally: It is the gap between natural language and thought on the one hand, and mathematical logic on the other. For example, the actual human thinking by which the cognitive scientists come up with their logical models is much richer and different than the logical models alone. But they don't encounter this because they don't refer to their own ongoing thinking functions and they don't attempt to apply their models to their actual thinking. It seems unscientific to refer directly to one's experienced thinking.

If our actual thinking can be referred to, then we can notice where our current logical models of thinking fall short. That would point up what functions cannot be formulated logically. Whether I should say "cannot" or "cannot yet" becomes an empirical question in the case of each such function as we encounter, point to, and gradually define each. I will be doing some of that in the rest of this paper.

The bridge-concepts I propose will help produce more and more of those logical formulations which seem to work alone and can become machines. But such concepts also constitute an increased understanding of our natural understanding. For example, now we understand one more way chess-masters think, a way that functioned implicitly before. Of course, while still implicit, it worked rather differently than it will from now on, when most chess-masters will have heard about it and think it explicitly. As bridgeconcepts, the terms "explication" and "implicit" can let us get at this difference, which explication will make, here. With these terms we keep the natural -- the more than logical -- side with us.

Now we dip into that side, to sense the change it makes, to explicate. We can then formulate and predict that chess masters who know this early-late strategic difference explicitly, will use it more often. We can also make a concept to say that what is explicated is severed from the many other dimensions which functioned together with it before. Before it was implicitly governed by all those other dimensions which crossed with it. The lack of this crossed governing might throw off a master's game, at least at first. As in a sport, you are thrown off while you are taught explicitly to hold your arm a certain way. By examining such thrown-off games with more dipping, the masters might find -- and tell us -- some of these other implicit dimensions, too. 
We also want a term and a study also for how -- after a while, as in a sport, this implicit crossing is re-established, and on a higher performance level. After all, more and more explication is the history of humankind: first it throws us off, then there is a reestablished implicit crossing on a higher level. By dipping we first make bridge-concepts, and from them we move to logical formulations and empirical predictions.

In psychotherapy, too, experiencing is more precise than can be said in common phrases. To refer to such experiencing and express it leads to deeper therapeutic change. (FOOTNOTE 1) ${ }^{1}$ Explicating changes it, and leads to renewed dipping and another change-step, and another, to more and more new experience.

Some psychotherapists, once they notice that a patient fits a diagnostic category, forget the patient and relate just to the category. Such therapists unconsciously keep their patients from changing. Because this pitfall is well-known, other therapists refuse to use any concepts, lest this happen to them. But if one knows that conceptual inferences are only one side, if one always relates again freshly to the patient -- or, in our terms, if one keeps dipping into the natural side -- then concepts sensitize one to what one might find. Then concepts help, and better ones would help more.

At first, many people are surprised that one can speak and think from experiences that are not already in the common phrases. As one client put it: "We were taught, that whatever we may feel, it could only be one of three or four things." He got very excited, and said: "If there is another way to think, I want it!" Here he as much as asks for the dipping as the concept-formation process I propose.

How does "dipping" happen? At first it brings one's attention, not to new clarities, but rather to something muddy, a murky body-state -- a felt sense. It may seem as if it were something private, merely an inner feeling-tone. But the subjective side is not private. When explication comes, it shows that a felt sense is all about the world.

You can check this, by pausing now, to engage in dipping. Let your attention refer inside, directly, physically, to the comfort or discomfort in the middle of your body. I want to ask you just about my talk so far (not about your other situations). About my talk, in the middle of your body, there -- what comes there -- about what I am saying? Is it all neutral and at ease there about that? Or is there some excitement, or some unease. Perhaps there is a sense of much that seems not quite right in what I am saying. Whatever body-sense is there, are there not many arguments implicit in it, which you could explicate if you had a few moments' peace?

A felt sense can implicitly contain arguments -- about the world. It is not just private, because we live -- sentiently, bodily -- in the world. A great many factors cross in such a single felt sense. Some have been separated out before, many have not. Your felt sense implicitly contains all you have heard me say, but also much that you have thought and read about these topics over the years, and your own work in all its many relevances - and much more, all crossing so each implicitly changes, governs and gives relevance to the others. And also, such a felt sense can lead to something new about the world.

So it is obvious that the subjective, bodily side is not private. No, the ..... is just as public and interactional as the language. Your felt sense is your body's interaction with 
your situations. Human bodies have situations and language implicit in them. Our bodies imply every next bit of our further living. An action can explicate this implicit further living, and can carry it forward. To explicate in words and in logic are special cases of such further living. So, of course, dipping into a felt sense brings what we want to do or say next.

Therefore dipping or focusing (Gendlin 1970, 1981, 1991) on a felt sense has become important in many fields, including the teaching of writing (Elbow 1988). That shows us something about language. People write more effectively when they focus on their felt sense of what they want to say. As a result of such dipping, they can write more precisely what they meant to say. Re-reading that, and dipping again into the felt sense of what they wrote, can lead to something even more precise.

How do words come when we speak and write? All we do is to await their coming. As we sense what we are about to say, the seemingly right ones usually roll out. But, if they don't come, we can only wait and try again. Words have this kind of coming, like sleep, the appetites, orgasm, love, tears, and much else. We cannot force those either. If they don't come, we can only wait. The body performs certain functions in language, for example the coming of words.

But, there is no split between the words and what we want to say. That also comes from the felt sense, and dipping lets it emerge with steps of increasing precision and clarity.

I have presented some bridge-terms so far, including subjective side, felt sense, direct reference, implicit, explication, and carrying forward. Now I have added steps of dipping, and, with my chess example, the loss and re-establishment of mutual governing by crossing. But the subjective side is not metaphysical. Rather, these interface terms define (themselves by) certain functions. Let me expand on this term "crossing," to show more such functions.

\section{II}

Both Lakoff (1987) and Johnson (1987) in their new books talk of something that is not just a pattern or a logical form. Johnson speaks of "concrete and dynamic, embodied imaginative schemata," which are surely not just logical patterns or images or diagrams. Lakoff talks of something "non-propositional." They have taken up an excellent strategic position, right on the interface, where they can assert both this embodied character, and also work on the logical side to collect and formulate what I have been calling "patterns that can be the same."

But, we can go further, if we distinguish: I will argue that the embodied nonpropositionals should not be thought of as if they were commonalities, classes, structures, or image schemata, although, we do also want to formulate those. I will try to show that the embodied non-propositionals function differently, not like commonalities or image schemata. We want to study their very different functions too. 
Wittgenstein showed that the meaning of a word lies in how it is used, and that it is used in a variety of situations. He would show that the same word could be used in many situations and would mean something different in each. He would offer, not three or four, but perhaps thirtyfour examples of such situations, each quite different. None of them would fit the pattern that initially seemed to define the word.

He showed that a word's use-situations share no single concept, pattern, image, or logical form. Nor are there cleanly divisible sub-kinds, either. He said that a word's uses share "only a family resemblance." The word's meaning is our knowing-how-to-use it, much as we know-how-to-ride-a-bicycle.

Wittgenstein did not go further: He could not even convince people to go as far as he did. His work led to thirty years of effort to define the use of words after all, if not by common forms, then at least by situational rules. The effort failed, and led to general discouragement. Today it is widely said that there is no order at all, since forms and rules fail.

But why not take the way words work by use-families as a positive fact, and study it? Why not try to understand and use how language exceeds fixed forms? Why not quite deliberately think with both forms and how they are exceeded in use? This has seemed impossible because it was assumed that only forms can be orderly, that "order" means exactly form. Then an exceeding of forms must undermine anything we try to say, think, or understand. It has led to nihilism or relativism.

Dare we think in more than patterns? But we always do. Only, this has been considered a terrible problem. Instead, let us make a positive and helpful fact of it.

Can we think and say a word's use-family? Of course. We think it whenever we say any word just by itself. For example, what does the word "use" mean, just taken alone? We get a felt sense of usage, daily use, usefulness, and the resentment we feel when someone only uses us. These meanings could not all apply in one case. But they are all implicit in this sense of knowing-how-to-use the word. Yet we can use the word quite precisely. This precision has not been accounted for. If by itself, a word means this family of many situations, how does it come to mean only just what it means in one situation? There it surely cannot mean all of its use-family. In use it always means something more precise. The word indeed brings its whole use-family, but brings it into one situation, so that both the family and the single situation determine together what the word means.

It is obvious that there is some (very familiar) relation between the variety of uses that a word brings, and the specific kind of situation in which it is actually used. The usefamily doesn't alone determine what the word says. Neither can the present situation simply change what a word means. Rather, both participate in determining what the word says here. The whole use-family crosses with the situation, and thereby the word makes just the sense it makes.

We can look more closely at this intricacy of a use family: The many uses are not just separate, as if next to each other. A use-family consists of actual uses, each of which has already crossed with the whole family. A use-family, our knowing-how-to-use a word 
-- is a crossing, and any actual use must be a fresh crossing, else we would not know what the word says here.

So we see that these many different situations are all crossed in our felt sense of familiarity with a word. This crossing of these many situations is a linguistic function performed by our felt sense of knowing-how-to-use the word.

But, there is also a second function involved here: A human situation is always part of a second variety of situations: What the girls' situation means involves a more extended story, not just the here and now, but also her upbringing, what her family will say and what will happen later on. The meaning of what we say here always consists also of how it changes some of our other situations. These other situations are all implicit together in what a situation is. This is a second function: we act and speak to carry forward a whole story consisting of many implicit situations.

These are two different linguistic functions which create two implicit groupings of situations: The other situations that make up the meaning of this one are a different grouping, not those situations in which the same word would be used.

The diverse kinds of situations in which a word can be used all cross in our knowing how to use the word. Secondly, a human situation is the kind of situation it is only because it implicitly involves many earlier, later, and related other situations which cross in it. And there is yet a third function: how these two crossings cross to make the meaning of the word in this kind of situation.

This very familiar way in which a word works in a situation involves not only these three function, but also a fourth: In addition to the specific kind of situation, there must also always be a sense of the actual situation in which we find ourselves. Many situations are implicit in any one, but we always know which one is present now. Words in themselves are general; but we speak and read not only in their generality, always also in the particular situation. This is a fourth function performed by the subjective side, not by commonality patterns. After all, the words are general. Even words like "you," "now," "here" only mean this situation by your direct reference to your felt sense now. As common forms they can be said anywhere. That they come into a particular situation is always known in advance, and is part of what determines which words come, and what they will say. This "deictic function" (Galbraith 1989) is also part of the familiar way in which words come into situations.

This familiar relation has been studied, so far as I know, only in a certain special case, called "metaphor," when a word is used in a situation that was not already part of its usual use-family. In that case it was noticed that there is a crossing between the usual use of the word, and a present situation.

Classically, metaphor was said to be a crossing between two single situations. My first modification of the theory is to argue that there is only one single situation, the new one. The so-called old situation is not actually a single situation, but rather the whole usefamily. The word brings all of its many, many old uses into this new situation. What crosses are not two situations, but a use-family and a situation. 
This is so, not just in metaphor, but in the usual use of any word. Its vast usefamily must cross with the single situation, for the word to work as it does. This fact has not been fully appreciated.

Let us study these functions. For example, without specifying a situation, let us ask people what the word "rose" means. They will probably describe its red color, its shape, the petals. They might think of roses in a garden, or a rose-pattern on wall paper, or a dozen long-stemmed roses in tissue-paper.

Now we read them some lines from a poem about a girl standing in a field. The poem says that she "is a rose." Crossed with this situation, now there is a single rose growing quite alone on a field. Let us now ask them what girl and rose have in common. ${ }^{2}$

What will they say? Like the rose, the girl is alive, fresh, young, soft, seemingly ready to be picked, both are poignantly time-limited, should be touched tenderly, can fight back and scratch someone bloody, will die while the person (a man) is only scratched, the double standard ....., all these and many more, an endless chain.

My second modification of the theory: The commonalities do not determine the metaphor. Rather, from the metaphor, and only after it makes sense, is a new set of commonalities derived.

My third modification: There is not a single pattern in common. A metaphor generates an endless chain of commonalities, not a single pattern.

No, the crossing of girl and rose is not a pattern, nor, we realize, is a girl a pattern, nor a rose. The girl's situation is not just the here and now. A human situation implicitly includes other situations -- what will happen to her, how her life will change, is the meaning of what happens here.

Like any word, the word "rose" brings the crossing of many possible usesituations. But the other situations where "rose" can be used are not the other situations of the girl. Rather, crossing these two crossings produces the sense the word makes here.

In addition, the poet knows in advance that the readers are always also in their own actual situation of reading a poem. If we did not always feel ourselves in a present situation, we would have been the girl standing in that field.

With any metaphor, we can also derive an endless chain of differences. We formulate these when someone did not understand a metaphor. Then we specify what the metaphor did not mean: It did not mean that the girl is rooted to the ground. No, she is not a plant, not dependent on rain, no petals, and so on. Again there is an endless chain, not one pattern-difference. But, granted they are many, do they function as patterns? For example, we had "time-limited" as a commonality. Surely that can be taken as a pattern in time. One of our differences was that the girl is not rooted to the ground. But, suppose now that the poem goes on to say that she stood "rooted to the ground." Said in general about a girl that would seem absurd, but in the poem it can say something: Perhaps she is earthy, or perhaps she is deeply part of her native culture. In the poem's situation the story says that she "stood stock still, timeless, rooted to the ground," when a man surprised her on her walk in the field. 
At first we took "no roots" as a spatial pattern -- the human shape has no thin strands dangling down. In that way it was one of our differences. Taken as a pattern, it remains false that her human shape has roots. But what crosses with a situation is not that space-pattern of roots. The metaphoric function is not performed by the space-pattern. So my fourth modification of the theory is that even the many retrospective commonalities are not just patterns. In further word-use they function differently than patterns do.

When experiential intricacies cross, the result can be new, and not logically consistent with how each seemed to be, alone. In a crossing neither functions as it was. Rather: each functions as already cross-affected by the other. Each is determined by, and also determines the other. If they functioned as logical patterns, they would limit each other down to a much smaller overlap. But: In crossing each opens the other to a carrying forward which makes new possibilities. The more determinants cross, the more novelty is possible.

Now again we can generate seeming commonalities in what "rooted" means here: It means immobile, not backing away, choicelessly facing someone, drawing firmness from the ground ..... We can take these as patterns; for example, as no shift in space over time. But such patterns are not what governs the next use of the words.

So also the differences: The metaphor doesn't say that part of her is underground, that she sucks water from the earth, and so on. But we also see now that if the poet did make one of those statements, it would not be the patterns that would function to make it possible.

A pattern is the same wherever asserted, and its assertion remains true or false. As we see, these patterns do not determine word-use, since the next use can contradict the pattern. If the phrase "she sucks water from the ground" did become seemingly common to them both, still -- it won't be the same pattern. So, even after the crossing, even in the metaphor, the seeming commonalities are not patterns. They do not say the same thing, for example about rose and girl. The same sentence can indeed be said of both, but it does not actually say any same things or same pattern. What it has said is not a same thing in two places. We see this fact from how we can go on about the one -- very differently -from the same sentence said about the other.

Only if we don't go on, can we take the commonality as a pattern. This choice of various ways of taking as is another function performed by the subjective side, to let the same sentence function either taken as a same pattern, or as it might work in further word-use. We can see all this right here: Let me say: "Following this paper I will lead a discussion." In this slot, and in this situation, what other words might I use? The usual words: I will conduct, moderate, hope to stimulate -- a discussion. Rather newer ones: I will beg for, implore a discussion. I hope to cook the discussion -- make it something good for all of us. Even conjunctions can say something when they come here: I promise to and your many viewpoints, rather than to but them. Once some words have worked in a slot, the slot can also speak alone: I will try to ..... our discussion. Since the slot can speak even when empty, we see that the slot contributes to what a word will say in it. ${ }^{3}$

It might be that all words can say something in any slot, but in order to do so they do have to work, make sense. Making sense is more precise than patterns. 


\section{Conclusion}

I have cited many essential functions in language, which are performed by the subjective side. My interface terms define, and are defined by, these functions. Especially I emphasized three crossings at work in metaphor and all word-use. These were the usefamily of a word, the implicit situations inherent in what any one human situation means, and how these two groupings cross in the actual use of any word.

I argued that in metaphor and in all word-use, a use-family and a situation cross, and that an endless chain of seeming commonalities can be generated only from -- and after -- the word has crossed, worked, made sense. I argued that although these seeming commonalities can be taken as just patterns, (as the same in various places), they can function in other ways and often do.

Of course our use of words is not always new in every way. We use the same crossings again. Therefore it is valuable to collect these seeming commonalities. They can let our formal logics and machines recognize the metaphor and the word-use. But we need the interface terms, both to extend the formal side, and to think of the functions that are not performed by the formal side.

A situation does not have a fixed pattern that can be just represented or read off. It is the nature of situations, that they can be re-structured with words. Metaphors and word-use can further structure any situation, not just "indeterminate" ones. If we could use only our common store of meanings, anything said or written could tell us only what we already knew. It would be dull.

In crossing, truth cannot be representational, not the accuracy of a copy. Rather, there is a truth of what can cross -- what can make sense. We can understand each other, across different experiences and different cultures, because by crossing we create in each other what neither of us was before. Communication and making sense does not rest on pre-existing commonalities, as if we can understand only what we already know. Nor is it misunderstanding and distortion. Rather, when we are precisely and exactly understood, that is when we are most eager to hear how it has crossed in the other person. Crossing creates something in the others that is new to them and to us. That is why we like to hear their reactions. ${ }^{4}$

\section{REFERENCES}

Galbraith, M., "What Everybody Knew Versus What Maisie Knew: The Change in Epistemological Perspective from the Prologue to the Opening of Chapter I" Style, Vol.23, No.2, 1989.

Gendlin, E. T., "Thinking Beyond Patterns: Body, Language, and Situation." In: den Ouden, B. and Moen, M. eds., The Presence of Feeling in Thought, New York: Peter Lang, 1991 in press.

"A Philosophical Critique of the Concept of Narcissism." Chapter in: Levin, D. M., ed., Pathologies of the Modern Self: Postmodern Studies. New York: New York University Press, 1987.

"What Comes After Traditional Psychotherapy Research?" Amer. Psychologist Vol. 41, No. 2, $1986 \mathrm{a}$, pps. 131-136. 
Let Your Body Interpret Your Dreams, Wilmette: Chiron 1986b.

Focusing. New York: Bantam Books, 1981.

Experiencing and the Creation of Meaning, New York: Macmillan 1962, 1970.

Gilligan, C. and Wiggins, G., "The Origins of Morality in Early Childhood Relationships."

Johnson, M., The Body in the Mind. U. of Chicago Press, 1987.

Lakoff, G. and Johnson, M., Metaphors We Live By, Chicago: U. of Chicago Press, 1980.

Lakoff, G. Women, Fire, and Dangerous Things. Chicago: U of Chicago Press, 1987.

Sterner, W. H., "Computer Programming, Corricular Pluralisms, and the Liberal Arts." Paper presented at: "Systematic Pluralism: An Interdisciplinary Conference." University of Nebraska, Lincoln, April 1990.

\section{NOTES}

${ }^{1}$ Characteristic language forms have been found reliably to distinguish this kind of steps. On taperecorded psychotherapy they can be distinguished from event-reporting, intellectual analysis, and emotional expression. These steps involve a silence, (a ....), after which the problem being discussed shows some change, novelty, or new detail. (Gendlin, 1986a\&b, 1987)

${ }^{2}$ If one says "A cigarette is a time bomb" people can state the common feature. But, if one first asks them to write the main features of a cigarette -- before hearing the time-bomb metaphor, they will not list that feature.

${ }^{3}$ For example, when we move from one theory to another, we can ask: How much of what the first theory showed is still implicit for us as we use the second? The first one seems to disappear. But usually just about everything it showed is there to cross with the second one. From then on, that theory no longer says only what it did before. Even though we assert only it, and not the first, the crossing that lets it make sense now includes also what we saw from the other theory. Logically we cannot merge the two theories, the two differing sets of forms. That would only deprive both of them of their power to say anything. But at any one juncture, we can articulate the more intricate crossing, if we permit ourselves to generate new phrasings and concepts.

We can study these functions. Once we have a slot in a sentence we can observe the words changing as they come into the slot. We can observe what people do with a slot, if given a series of replacement words. Since some past uses have been formulated, we can examine the more precise use the word acquires by crossing with the slot. We can also observe how, once a word has worked in a slot, it continues to work implicitly in how the next word works there.

${ }^{4}$ Gilligan argues against Hoffman's assertion (the usual one) that "one can feel another's feelings only to the extent that the other's feelings are similar to one's own." Gilligan says that "Considered on a theoretical level, co-feeling, however morally desirable, would seem to be psychologically impossible." Then she cites many findings that "co-feeling implies that one can experience feelings that are different from one's own." We see here the grand error of most Western theories -- the assumption that all cognition must consist of pre-existing patterns or units. All about us we see novelty instead. That certainly includes the crossing when two people interact. 